Utah State University

DigitalCommons@USU

\title{
Initiating Cultural Shifts in Perceptions of Cataloging Units through Interaction Assessment
}

\author{
Andrea Payant \\ Utah State University \\ Becky Skeen \\ Utah State University \\ Liz Woolcott \\ Utah State University
}

Follow this and additional works at: https://digitalcommons.usu.edu/lib_pubs

Part of the Library and Information Science Commons

\section{Recommended Citation}

Payant, Andrea; Skeen, Becky; and Woolcott, Liz, "Initiating Cultural Shifts in Perceptions of Cataloging Units through Interaction Assessment" (2017). Library Faculty \& Staff Publications. Paper 275.

https://digitalcommons.usu.edu/lib_pubs/275

This Article is brought to you for free and open access by the Libraries at DigitalCommons@USU. It has been accepted for inclusion in Library Faculty \& Staff Publications by an authorized administrator of DigitalCommons@USU. For more information, please contact digitalcommons@usu.edu.

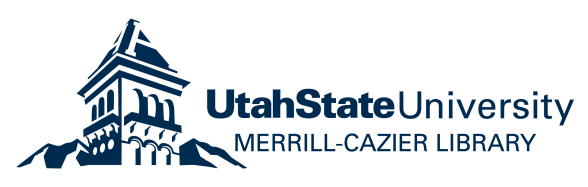




\title{
Initiating Cultural Shifts in Perceptions of Cataloging Units Through Interaction Assessment
}

\author{
Andrea Payant, Becky Skeen, and Liz Woolcott \\ Cataloging and Metadata Services, Merrill-Cazier Library, Utah State University
}

\begin{abstract}
Alt. Title: Changing perception through interaction assessment
Abstract: Points of contact formulate the culture of any organization and shape the perceptions of decision makers and colleagues alike. This research project investigated the interactions between Cataloging and Metadata Services staff and other library employees by analyzing interactions. This paper summarizes the results of data gathered from interaction assessments and compares them with surveys about the current perceptions of the cataloging unit at the Utah State University Libraries. It discusses the ways these results have influenced existing unit workflows to enhance awareness of cataloging and metadata contributions to the library and posits possible ways to continue such initiatives moving forward.
\end{abstract}

Keywords: interaction, assessment, culture, perception, cataloging 


\section{Introduction}

As is likely the case with many cataloging and metadata units within academic libraries, the Cataloging and Metadata Services (CMS) unit at Utah State University has confronted the challenge of shrinking staff and changing roles over the last decade. Catalogers and technical services in general, are sometimes undervalued as contributors to the field of librarianship due to the complex and "behind-the-scenes" nature of the work they do. This labyrinthine work, dependent on a mosaic of bewildering standards and rules and more visible for its failures than successes, is easily trivialized as unnecessary, excessive, or outsource-able. For example, a common mistake is the assumption that implementing shelf-ready has eliminated most of the work that catalogers do, without much thought to providing access for original material (whether archival collections or the budding field of data and institutional research products) or the current shift to batch loading work that moves and manipulates records in previously unimaginable quantities. Just as often, the value of cataloging is hampered by the caricature of the "cataloger" as individuals who prefer to work alone, who are dogged perfectionists, inflexible, uncompromising, and unnecessarily overcomplicate everything. Separating the work of the cataloging unit from the rest of the library allows for efficiencies in labor division, but ultimately engenders long-term isolation that leads to dwindling resources, staffing, and sometimes even respect, particularly in a field abuzz with words such as "collaboration" and "cross-departmental." A variety of proposed ways to combat this trajectory have focused on the cataloging unit moving outward to incorporate more with the library, such as working public service desk shifts. Some have even looked at drawing colleagues in by job shadowing or training. Both of these examples are well worth considering.

This research project, however, aimed to develop a new data-centric approach by recording and mapping out interactions between CMS unit members and the rest of the library staff. The end 
goal of the process was to test if proving the value of cataloging was really a matter of education or communication. The interaction mapping was compared against a survey of the perception of the CMS unit to test if there were correlations between frequency of interactions and positive views of the unit. Outlining the topography that defined the CMS unit's impact identified key areas of strengths and deficits in communication and interaction. The data even supported that many of the long held stereotypes of catalogers do not hold up to scrutiny. Overall, it allowed the CMS unit to develop data-driven strategies to increase engagement with the library.

\section{Literature Review}

A survey of existing literature revealed that no significant measures have been taken to assess specific interactions between catalogers and other library staff. Despite the apparent lack of this kind of assessment, there are a number of notable articles that provide valuable insight into different attitudes toward cataloging. Some of the literature seeks to demonstrate the value of cataloging services while others identify established perceptions of catalogers and cataloging work and advise on how to change possible misconceptions. Other recent themes concentrate on roles, or evolving roles of catalogers, which have been necessitated by the implementation of RDA and recent developments involving Linked Data and the slow progression away from traditional MARC cataloging. Generally, these works appear to be congruous with no apparent opposition to the observations or assertions made by the authors.

There is a consistent theme in the literature showing evidence that the cataloging profession is greatly undervalued. Authors have made efforts to bring this fact to light and offer suggestions for solving this problem. For instance, Borie, MacDonald, and Sze observe that “...catalogers have a unique challenge to overcome in demonstrating the value of their services...[and] the better they are at performing their work...the more invisible their efforts are to users and 
administrators." They assert that since catalogers work out of the public view that they are often not "...conceptualized as a public service, even within libraries." Miksa offers parallel remarks on the difficulties catalogers must face in that they "... often have to endure misunderstanding of their jobs from colleagues, patrons, and administrators." ${ }^{3}$ CannCasciato ${ }^{4}$ and Borie, MacDonald, and Sze ${ }^{5}$ refer to a statement titled "The Value of Cataloging Librarians," published in $2007^{6}$ with the sole purpose of assisting managers in describing the crucial need for cataloging librarians. CannCasciato observes "...there appears to be no similar existing statement for other specializations in librarianship."7 This suggests that other library professions are not likely burdened with the obstacle of defending their worth.

Among the relevant literature that addresses perceptions of catalogers, we find that there are generally negative sentiments associated with the profession and individuals employed therein. For example, Banush discusses long-held stereotypes connected to academic catalogers. He relates how they are often seen as back-room hermits, surrounded by books, and as unwavering perfectionists unconcerned with the library outside their cubicle or office. ${ }^{8} \mathrm{He}$ states that this "...image has long been a misrepresentation of the actual contributions of catalogers to library users...[and] its persistence suggests that even as it becomes increasingly incongruous with reality, it remains a powerful force, one which influences the perceived importance of catalogers' work while also limiting their potential for contributing to a more holistic view of librarianship." Hoerman echoes this assertion and frankly describes witnessing "...a great deal of disparagement of cataloging..." and that there is "...distaste for cataloging among library school students, experienced librarians, and administrators." ${ }^{10}$ Unfortunately, there seems to be no clear explanation as to why these stereotypes continue, but all the authors concur that opportunities for catalogers to take part in the broader purpose of the library are abundant. They also conclude that it is catalogers who will need to make the extra effort to participate 
more actively to change these false perceptions and work to find ways to expand beyond traditional roles.

In addition to these difficulties, it is clear that catalogers are also expected to adapt and evolve as quickly as changes occur in the cataloging, metadata, and library fields. For example, Boydston and Leysen discuss findings of a 2011 study regarding changing cataloging roles and responsibilities. ${ }^{11}$ They conclude that cataloger librarians will be required to develop or expand their skills, especially at a higher technological level, if they expect to "... be a part of emerging trends and communicate with internal and external partners and communities." ${ }^{12}$ Banush also emphasizes the same point as he describes how the role of catalogers has evolved at the Cornell University Library. He writes about how the most traditional cataloging roles are currently being carried out by “...highly-trained non-MLS staff [while] MLS-holding catalog librarians have in turn taken on significant roles in other library activities."13 Other authors, like Folsom, discuss some potential roles for catalogers and technical services librarians. The focus of Folsom's research seeks to address how catalogers can transition into roles in public services and relates how they bring valuable qualities to this aspect of librarianship. Folsom lists catalogers' high level of technical skill, knowledge of database structure and design, and overall understanding of technical services as having particular value in a public services role. ${ }^{14}$ Likewise, Turner and Nann explore the possibilities of technical services librarians playing a role in teaching information literacy. They explain the need for these groups to be part of the academic conversations and that technical services librarians have an "...intimate knowledge of workflow in their own department that may impact the library's efforts in information literacy." 15

Most of the authors mentioned previously offer helpful insight into possible solutions for addressing the issues of misconceptions, underestimated value, and changing roles of cataloging librarians. Based on their observations, one can easily conclude that the best 
solution lies on the shoulders of the catalogers themselves. For example, one recommendation is to "...learn to communicate in the language of administrators and users, using approaches of broad appeal that speak within and beyond the cataloging community." 16 Similarly, they advise improving communication so that administrators are made aware of the effects of an investment, or lack thereof, to employ catalogers by demonstrating the need for their expertise in providing the highest level of service ${ }^{17}$ Others encourage thinking broadly about roles and not being limited by a specific job description, ${ }^{18}$ or they suggest exploring new ways to provide access to library information. ${ }^{19}$

\section{Interaction Logs}

Understanding the current interactions that build the foundations of library relationships should provide insight into the perpetuation of cultural perceptions about catalogers and cataloging work. The Cataloging and Metadata Services unit at Utah State University developed a methodology to analyze the frequency, format, and purpose of the interactions that occurred between the unit and the rest of the library. This assessment metric was used to formulate an overall understanding of the communication patterns in order to identify deficits and areas of growth or potential outreach.

The CMS unit staff ("staff" being a term all USU Library employees are called, regardless of position or faculty/non-faculty status) were asked to track their interactions on a weekly log. Throughout the week, unit staff would track each meeting, phone call, email, or interaction during his or her normal work hours with any non-CMS library employee. Interactions within the unit were not counted as part of this process. Interaction tracking continued for four weeks and the information from the physical tracking sheets was entered into a spreadsheet at the end of each week. The options and layout of the log sheet were vetted over a two-week trial run prior 
to the official tracking period. Data collection for the interaction logs took place for 18 workdays over 4 weeks, totaling one month. (Note: the University was closed two days during the assessment period. The data outputs described below were weighted to exclude the days that no interaction was expected.)

The interaction log was designed to not only collect the data needed, but also to fit easily into the daily work of the CMS staff to ensure consistent, timely use without interrupting workflows. The log sheet was constructed to track: name of the recorder; date and time of interaction; name of the library department interacted with; who initiated the interaction; method of interaction and communication; length of conversation; reason for interaction; and a notes field for any comments the author might want to make about the encounter. Whenever possible multiple-choice answers were utilized to facilitate the speed of data capture and provide standardized categories. In typical logbook fashion, the form was set up with column headers and legends for the multiple-choice answers. The log was structured to have one entry (i.e. interaction) per row with the optional note field available at the end when more information was needed for that particular log entry. (See Figure 1.)

Week 1 Cataloging Interaction Log for

Legend for "Reason for interaction": $\underline{\mathbf{a}}=$ Database questions (Sierra, CONTENTdm, etc.); $\underline{\mathbf{b}}=$ Request assistance; $\underline{\mathbf{c}}=$ Procedures/Workflow questions or issues; $\underline{\mathbf{d}}=$ Drop off $/$ Pickup of materials; $\underline{\mathbf{e}}=$ Meetings, Committees, Projects, or Training; $\underline{\mathbf{f}}=$ General Library issues; $\underline{\mathbf{g}}=$ Social (either inside or outside the workplace); $\underline{\mathbf{h}}=$ Patron-driven questions; $\underline{\mathbf{i}}=$ Reference desk; $\mathbf{i}=$ Other (please explain in notes area)

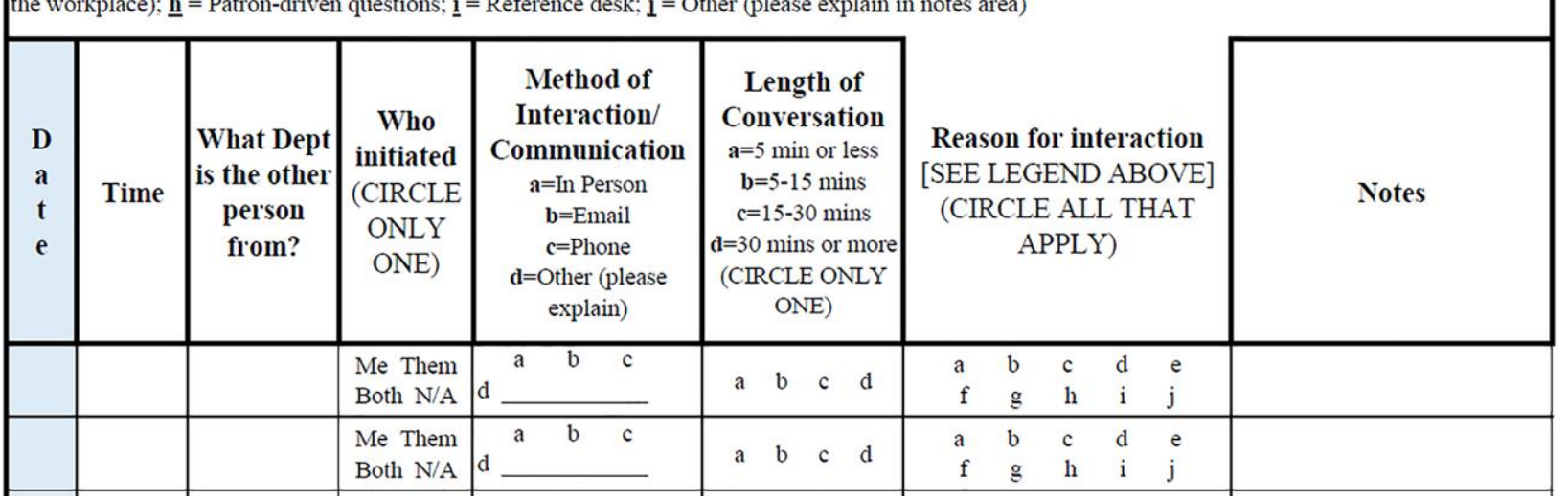

<Fig. 1. Example of weekly interaction log.> 


\section{Structure of the Cataloging and Metadata Services Unit at USU}

Before investigating the results of the interaction log, a brief outline of the organizational structure of the CMS unit will be necessary to understand the dynamics in the data. The unit is one of four units belonging to the Technical Services division. At the time the interaction logs and survey were conducted, the unit was composed of 5.5 full-time equivalent (FTE) professional catalogers, 3 FTE paraprofessional cataloging assistants, and 1 department head, with a total number of 10 individual people in the unit. All CMS unit staff are located in the same physical space on the second floor of the library, with the exception of one professional cataloger who resides full time in the Special Collections \& Archives unit, but reports to the CMS unit.

While each professional cataloger has a specialty, there is considerable cross training that allows them to move fluidly between specialties in response to the influx of collections and projects. For instance, the General Cataloger is responsible for cataloging foreign language material, as well as collections for regional campus libraries, the children's library, and Special Collections material, in addition to database maintenance tasks such as authority changes and withdrawals. The Metadata Coordinator aids with cataloging for regional campus libraries and foreign language material, in addition to managing the metadata creation for the digital library and providing guidance on metadata schemas for research outputs. The Government Documents and Special Formats cataloger does the original or complex copy cataloging for the Government Documents while also handling the individual title cataloging for electronic resources, all of the specialty formats (maps, audio visual, etc.), and contributes to the Special Collections cataloging efforts. The Serials Cataloger is the only professional that concentrates almost entirely on one specific cataloging activity, but she also oversees the authority control work for the unit. Each of the three cataloging assistants is cross-trained for traditional MARC 
cataloging and Dublin Core metadata assignments. One cataloging assistant helps with audiovisual formats, and regional campus libraries, general research collection cataloging, and metadata assignment for the Digital Library. The remaining two cataloging assistants copy catalog for Special Collections and assign metadata for the Digital Library.

\section{Analysis of Interaction Logs}

To completely understand existing perceptions of the Cataloging and Metadata Services unit, it is important to know which library units the CMS staff interact with the most. Analysis of this information found that the top five library units that the CMS staff were in contact with the most were:

1) Special Collections \& Archives (SCA) - 33\%

2) Library Administration - 16\%

3) Digital Initiatives - 10\%

4) Collection Development - $8 \%$

5) Acquisitions - 8\%

These five units accounted for $75 \%$ of all the interactions logged in this research project. Of that $75 \%$, almost half of the exchanges were with Special Collections \& Archives staff. There are a few possible reasons that may contribute to the high frequency of interactions with SCA, the most obvious being that the cataloger embedded in the SCA unit likely has more interactions with Special Collections staff on a daily basis because of where she is located. Another explanation for the high interaction rate is the library's continued emphasis on digitizing and creating metadata for the unique materials found in SCA. Finally, half of the Cataloging and Metadata Services staff provide weekly reference assistance at the SCA public service desk, which opens up the opportunity for more interactions between the two units. 
What proved to be the most surprising trend was the relative infrequency of interactions within the Technical Services division in which the CMS unit resides. (See Figure 2.) This division is also composed of the Collection Development unit, the Materials and Acquisitions unit, and the Resource Sharing and Document Delivery unit. With Collection Development and Acquisitions comprising just $8 \%$ of interactions each, and Resource Sharing and Document Delivery comprising just $2 \%$ of interactions, the question arose - what reasons lead us to interact more with other divisions than our own? This was even more striking considering that the Cataloging and Metadata Services unit resides in the same physical space as the Collection Development unit and next door to the Acquisitions unit. While one cataloger living in the Special Collections unit might drive up the number of interactions with that unit, shouldn't the remaining nine members of the CMS unit residing with and next to two other units do the same? This suggests that much of the communication differences were related to workflow rather than proximity.

Number of Interactions with each Library Unit

\begin{tabular}{l|r|}
\hline Library Unit & 46 \\
\hline Acquisitions & 91 \\
\hline Administration & 14 \\
Circulation and Library Media Collections and Reserves & 47 \\
Collection Development & 20 \\
Data Services & 55 \\
Digital Initiatives & 2 \\
Government Documents & 20 \\
Not supplied & 36 \\
Reference and Instruction & 12 \\
Resource Sharing and Document Delivery & 189 \\
Special Collections \& Archives & 36 \\
Systems & 4 \\
USU Eastern Libraries & 572 \\
\hline Grand Total & \\
\hline
\end{tabular}

Number of Records

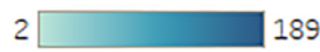

<Fig. 2. Library Unit and Number of Interactions. >

Further investigation of this question warrants a deeper dive into the reasons CMS staff were interacting with the rest of the library. The unit staff were asked to record the reason for their interaction with library staff outside of the Cataloging unit, with the available options being: 
- Database questions

- Drop-off/pickup materials

- General library issues

- Meetings, Committees, Projects, or Trainings

- Patron-driven question

- Procedures/workflow issues

- Public service desks

- Request assistance

- Social

- Other

When compiled, the most common reason for interaction was unexpected. Contrary to the stereotypical view of the quiet and withdrawn cataloger, the most common reason a CMS staff member interacted with library colleagues was for social reasons. Almost a quarter of interactions were defined as "social." When further broken down by who initiated the interaction, social interactions were also twice as likely to be initiated by the CMS unit member as by non-CMS library colleagues. (See Figure 3.) 


\section{Reason for Interaction}

\begin{tabular}{l|r|r|} 
Reason for Interaction & \multicolumn{2}{l|}{ Number of Records } \\
\hline Database questions & 17 & 2 \\
Drop off/pickup materials & 40 & \\
General library issues & 58 & \\
Meetings, Committes, Projects, or Training & 125 \\
Patron-driven question & 4 & 65 \\
Procedures/workflow issues & 31 \\
Reference desk & 29 \\
Request assistance & 140 \\
Social & 61 \\
Other & 2 & 572 \\
Not supplied &
\end{tabular}

<Fig. 3. Reason for Interaction>

The next most common reason for interaction was for "Meetings, Committees, Projects or Training." (Please note this category was broadly constructed to facilitate log sheet entry because defining the differences between committee meetings, project meetings, training meetings, etc. proved subjective and varied widely in the testing phase.) Both the social interactions and the meetings were significantly more prominent than any other reason for interaction, almost doubling that of "Procedures/workflow issues," which was the third highest recorded reason for interaction. This demonstrated an active engagement in the general work and operations of the library, apart from the traditional "backroom" perception.

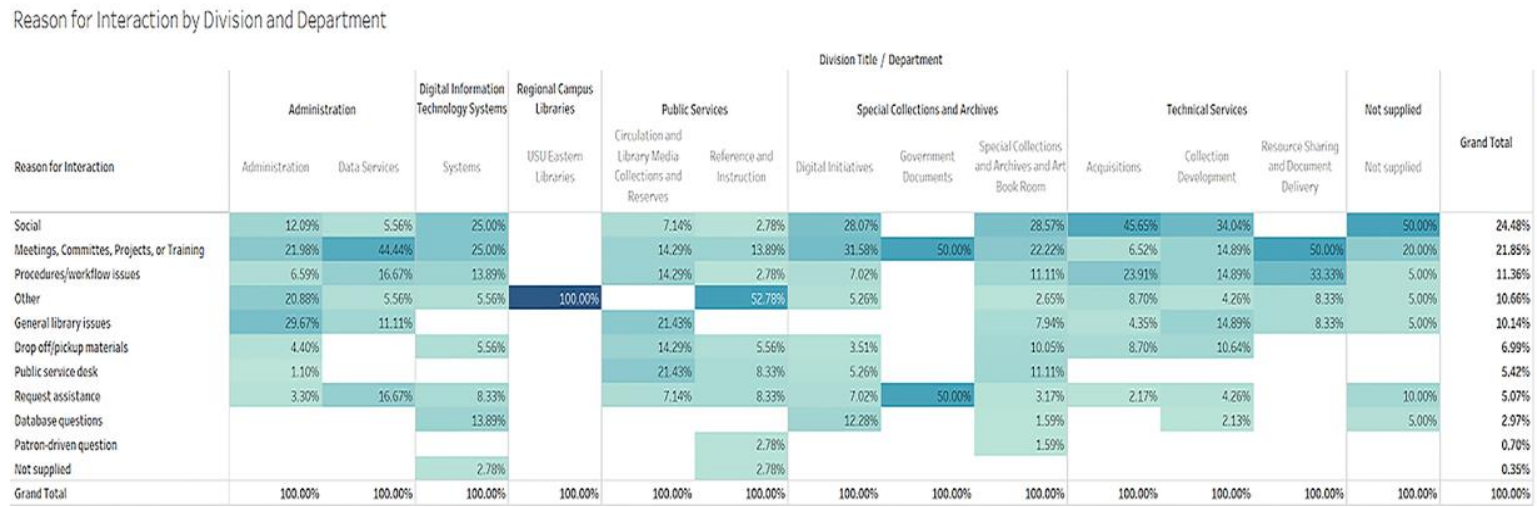

<Fig. 4. Reason for Interaction by Division and Department> 
Figure 4 demonstrates the reasons for interaction with specific units in the library, which revealed interesting trends. As previously discussed, the most frequently reported interactions were with the Special Collections \& Archives unit, which resides two floors down from the Cataloging and Metadata Services unit. And as the overall trend displayed above, the most common reasons for interaction were typically social (29\%), meetings (22\%), public service desk (11\%), procedures and workflow issues (11\%), or to pick up or drop off material (10\%). Overall, it appeared that the general work of the CMS overlapped significantly with the SCA unit.

Interactions with the Library Administration unit were the next most common division, but the reasons for interaction differ from the overall model, with "General Library Issues" accounting for $30 \%$ of the interactions. This is not surprising considering that the Library Administration is more concerned with overall library issues than with specific projects. Committees and meetings accounted for $22 \%$ of the interactions, and "Other" accounted for $21 \%$ of the interactions.

For the Technical Services division as a whole, social interactions cumulatively comprised $44 \%$ of the interactions and were over twice as common as procedure and workflow questions, which accounted for $20 \%$ of the interactions. Meetings and projects totaled just $8 \%$ of all interactions with our fellow division units. This may be due to impromptu discussions about day-to-day work happening between the members of the division, rather than regularly scheduled project or meeting-based work. It might also be indicative of a workflow that remains fairly constant over time, without requiring a lot of meetings or committees to maintain or update the process. Ultimately, though, these numbers appear to indicate a larger shift in Technical Services work away from conventional, labor-intensive workflows towards batch loading and large-scale maintenance of mainstream research collections, which is increasingly handled in USU library's Systems unit. This unexpectedly low number of interactions highlighted the need to re-analyze 
the larger patterns of the division workflows and the role of the CMS unit within them. Acknowledging and embracing the changing information ecosystem presents the unit with the opportunity to retool itself for a new model of content demand and information delivery. While the need for traditionally cataloged material is still very much present in the library, there appears to be a significant shift in demand for access to original content owned by the library. Up until now, this has been a niche concern, with minimal staffing thrown its direction upon request. The information gathered in this assessment demonstrated a need to retool the unit's skill set and re-assign dedicated duties to focus on original content description in multiple cataloging languages.

The following chart (Fig. 5) outlines the reasons that each of the CMS unit members had interacted with non-CMS library colleagues. As interactions with the Special Collections \& Archives division (composed of the Special Collections \& Archives unit, Art Book Room, Digital Initiatives unit, and Government Documents unit) accounted for $45 \%$ of the total interactions, it was unsurprising that the three of the four primary catalogers for SCA material (the Special Collections Cataloger, the Metadata Coordinator, and the General Cataloger) recorded the most frequent interactions (with the exception of the CMS unit head, whose interactions were heavily driven by meetings.)

The data also highlighted the lack of interactions between the CMS cataloging assistants and the rest of the library staff. While their work is more day-to-day and less of the planning or project management focused work, the three cataloging assistants showed a surprising paucity of every kind of interaction, including social. This demonstrated a need to create more opportunities for the cataloging assistants to engage with colleagues in other parts of the library. Work silos exist for more than just the library professionals or project managers in a unit. Compartmentalization creates divisions between units that can ripple into other, daily aspects of 
library work and cause cultural misunderstandings within a library, a lack of value for the work done in a different unit, and also a lack of understanding of how the workflows in a different unit impacts one's own unit.

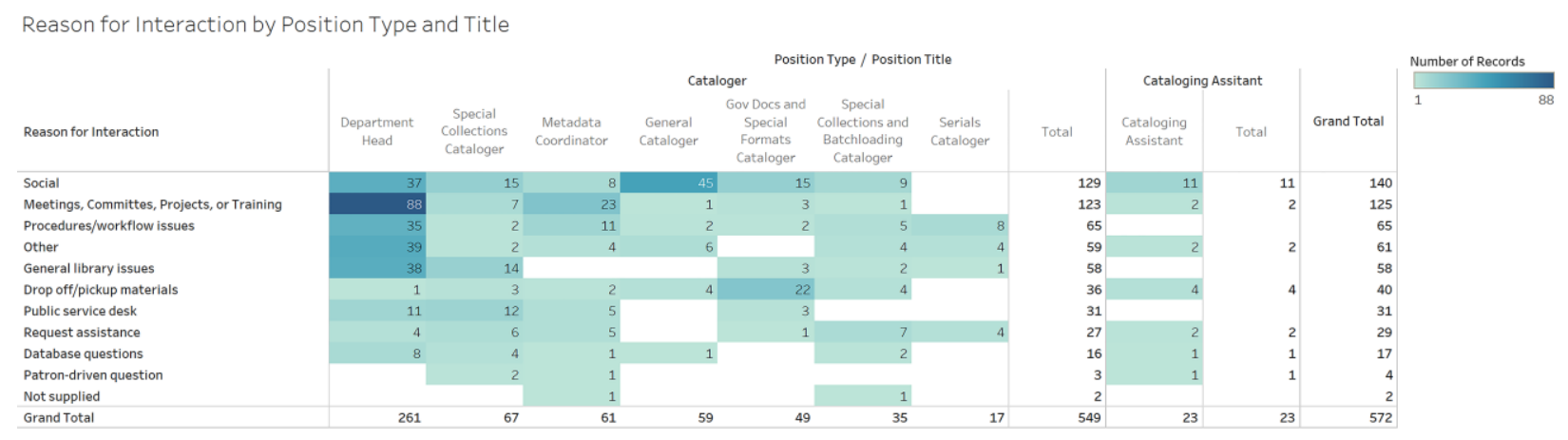

<Fig. 5. Reason for Interaction by Position Type and Title.>

In order to understand more about how interactions between CMS unit members and other units occurred, it was necessary for the interaction logs to identify and relate information about the origin of contact and the methods by which communications were established. Differentiations between those who initiated contact were made by including the option for those logging interactions to identify either party, both parties, or cases when identification was not applicable to any given situation. The methods of communication were tracked in the logs by including the following categories: in-person, e-mail, phone, and other (which usually described interactions achieved through social media platforms or text message). (See Figure 6.)

Overall, analysis of parties initiating contact showed that exchanges driven by Cataloging and Metadata unit members were the most common, but also that those initiated by others were at an almost equal percentage, with both factors adding up to $70 \%$ of the total. The data also showed that exchanges originating equally from both parties, or not initiated by either party, were at an equal percentage as well with both factors adding up to $30 \%$ of the total. The nearly equal percentages, shown respectively by the data, imply that there is a very balanced level of communication among all parties. One can, in turn, assume that this balance is evidence of an 
equal inclination for initiating interactions, which contradicts the "withdrawn and introverted cataloger" stereotype and further suggests a highly cooperative work environment.

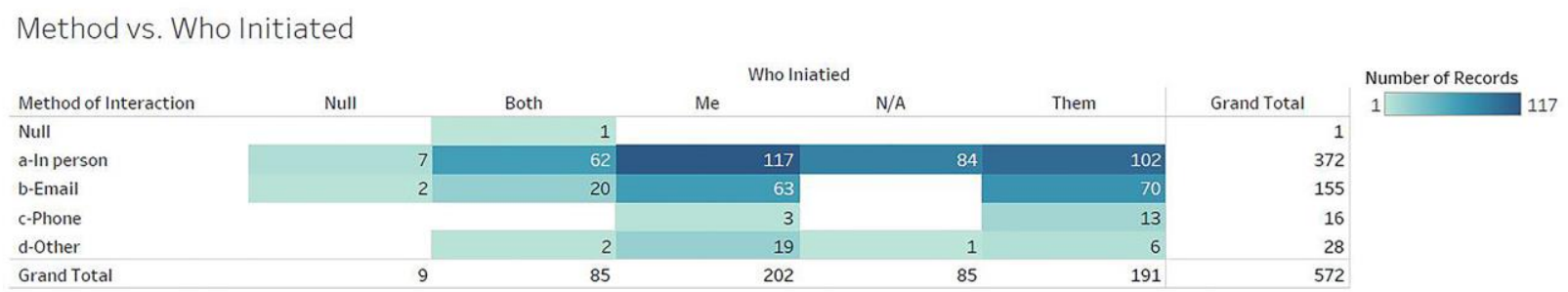

<Fig. 6. Methods of Interaction by Initiator

This trend away from the outmoded cliché of shy catalogers holds true when looking at the methods of interaction, which showed that the vast majority of exchanges were made in person. This data indicate that in-person interaction is likely the most effective and useful mode of communication across units. It also suggests that meeting in person is essential for accomplishing work tasks and therefore the high level of face-to-face contact is warranted.

A more detailed investigation of the methods of contact revealed that email interactions were the second most common mode of communication. Email exchanges, added together with the in-person interactions, made up $92 \%$ of the total. Working under the assumption that email exchanges were made mostly between two individuals, it is apparent that one-on-one communication is more prevalent than interactions involving groups. This suggests that crossdepartmental communication may be driven by specific purpose and focused on individuals' expertise and skill set.

When considering the days of the week that most interactions occur, the results strongly indicated that communication and engagement are 2 to 3 times more likely to take place on Mondays and Tuesdays. (See Figure 7.) Similarly, most interactions take place in the afternoons, with intermittent interactions in the early morning (before $8 \mathrm{am}$ ) or in the evenings (after 5 pm). 


\section{Interactions by Day of Week and Time of Day}

\begin{tabular}{|c|c|c|c|c|c|c|c|}
\hline \multirow[b]{2}{*}{ General } & \multicolumn{5}{|c|}{ Day of Week } & \multicolumn{2}{|c|}{ Number of Records } \\
\hline & Monday & Tuesday & Wednes.. & Thursday & Friday & & \\
\hline Early Morning & 3 & 1 & 2 & & 1 & 1 & 103 \\
\hline Morning & 67 & 55 & 38 & 20 & 12 & & \\
\hline Afternoon & 103 & 101 & 49 & 50 & 40 & & \\
\hline Evening & 11 & 12 & 4 & 1 & 2 & & \\
\hline
\end{tabular}

<Fig. 7. Interactions by Day of Week and Time of Day.>

The date and time of interactions data were useful in deciding how to approach new services that the CMS unit offers, particularly what times of the day were most important for unit members to be available to answer questions, participate in meetings, and receive or deliver library acquisitions. (See Figure 8.)

\section{Reason for Interaction by Time of Day}

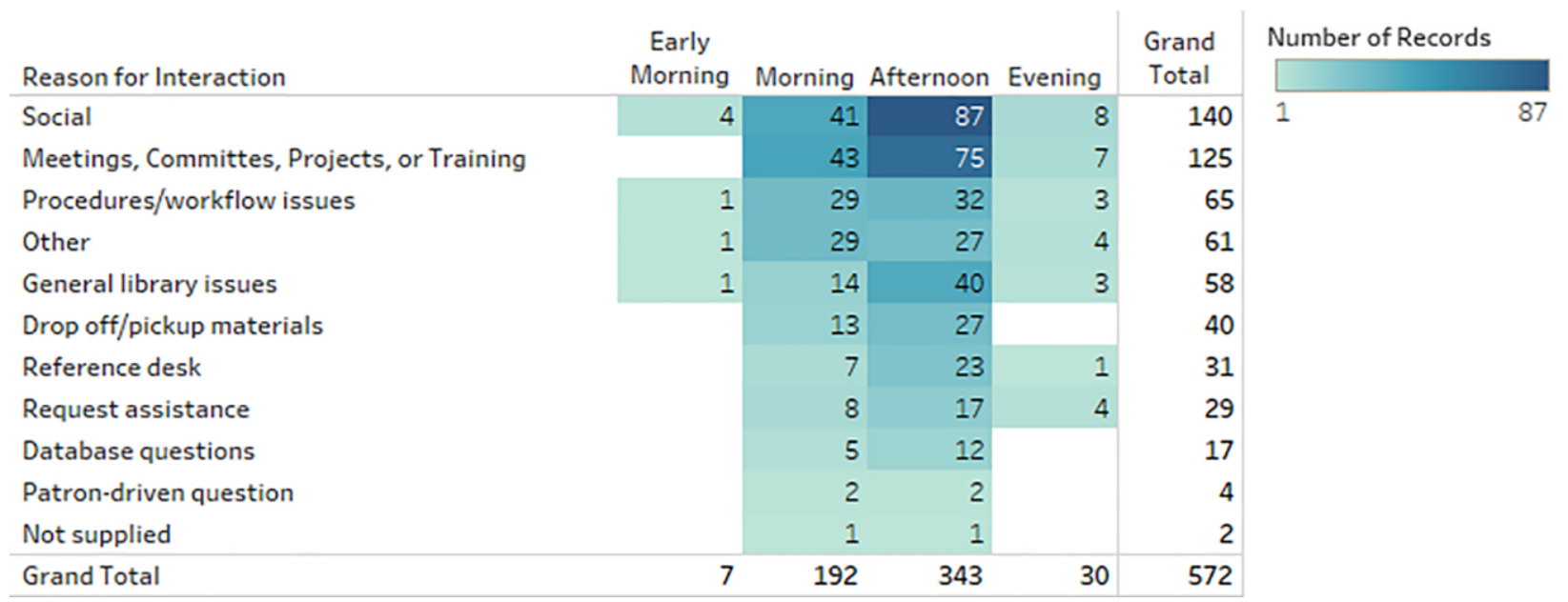

<Fig. 8. Reasons for Interaction by Time of Day.>

\section{Developing Initiatives}

The Cataloging and Metadata Services unit explored potential strategies to increase the utility and visibility of the unit to the rest of the library. While many possibilities were presented by the 
data and discussed by the unit staff, it was felt that workloads and project due dates required a measured approach to developing more interactions with the library staff. The unit members valued putting forward a couple manageable initiatives, measuring the effectiveness of those initiatives, improving them based on the feedback, and then exploring more options once the initial projects were completed or in place. The two exploratory initiatives decided on were a single service point model for quickly addressing issues in the library catalog and a series of infographics to educate about and trumpet the work of the unit.

\section{Single Service Point Initiative}

Under the CMS unit's old service model, when a library staff member had a cataloging or metadata related question, they would consult a large "Go-To" chart posted in the entrance of the unit featuring 80 options that outlined each cataloger's expertise. The CMS unit streamlined this process with the aforementioned initiative, referred to as the single service point model, by designating the most experienced cataloging assistant to act as the starting point for all questions. When approached with a question, the single-service point coordinator would investigate the issue and address any concerns that were within his purview, referring higherlevel issues to the appropriate cataloger, if needed. The single service point model was advertised to all of the library staff using library-wide emails and visits to other library unit meetings to highlight the purpose of the service and distribute the name and contact information for the cataloging assistant they should consult. This model met internal needs for streamlining unexpected work brought to the department and also met the data-identified needs for increasing interactions between the cataloging assistants in the unit and the rest of the library staff. 


\section{Infographics and Education Initiative}

The second initiative was an education and awareness push using data visualizations.

Infographics were created to exhibit the accomplishments and work of the CMS unit. Annual statistics, information about new processes the unit had innovated, and scholarly contributions to the field were translated into infographic visualizations, such as the example presented in

Figure 9.

INNOVATIONS AND SCHOLARSHIP
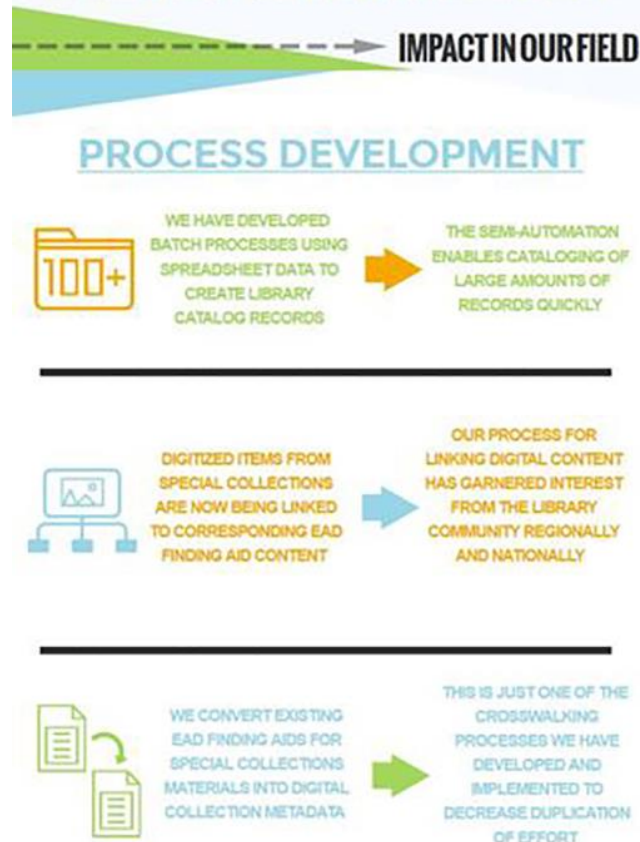

\section{SINGLE SERVICE POINT}

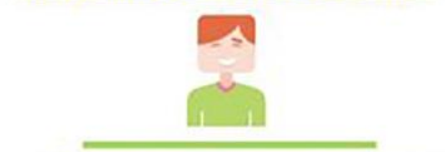

WE HAVE IMPLEMENTED A SEVGLE SERVICE PONT

MODEL. TO RESOLVE ALL STAFF ANDIOR STUDENT

NEEDS FROM THE CATALOGING DEPARTMENT

ITEM TRACKING

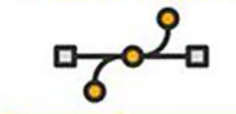

ALL TEMS ENTERING CATALOGING ARE NOW TRACKED WITHIV THE DEPARTMEETT SO WHEREABOUTS ARE ALWLAYS KNOWN AND PROCESSING TME CAN BE MEASURED MORE EXACTLY

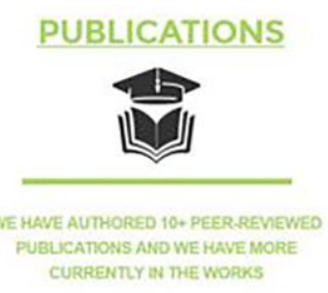

PRESENTATIONS

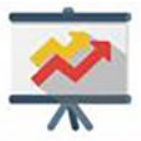

CURRENT CATALOGNG STAFF MEMBERS HAVE CONTRIBUTED CONTENT FOR A NUMBSR OF. PRESENTATIONS FOR LIBRARY ORGANIZATONS

1- INTERNATIONAL.

15 MATIONAL

16 - REGIONLAL

<Fig. 9. Example of one infographic used to visualize innovations and scholarship within the CMS unit.>

The infographics displayed data including facts about catalogers' knowledge of standards and formats, their service on committees, memberships in local and national library organizations, fluency with specific computer programs, and their years of combined service to the library. Additional infographics included timelines for completed large-scale projects, explanations of common obstacles that catalogers face when describing resources, and items from library collections that were particularly unique or difficult for our department to catalog. These were featured to further illustrate the cataloging contributions made to our institution. 
The infographics were printed using a large format printer and posted on walls and cubicles around the CMS office. Library administration members were invited to a luncheon in the Cataloging and Metadata Services area to view these accomplishments by the CMS staff and additional metadata and cataloging volunteers from around the library. With a heavy emphasis on casual conversation, the luncheon was an open house style that utilized the displayed visualizations as a focal point for generating discussion between the library administration and the CMS staff. The primary goal of the process was to both demonstrate the value of the cataloging work accomplished and to build relationships through face-to-face interactions. After the luncheon, the infographics were housed on the walls of the Technical Services conference room and displayed on the department blog. ${ }^{20}$

\section{Measuring Effectiveness}

Following the implementation of the single service point and the infographics, the Cataloging and Metadata Services unit created a survey to investigate the effectiveness of the two new initiatives and also more accurately define the library's cultural perceptions and expectations of the unit. Using a Qualtrics platform, the survey questioned respondents about their perceptions and assessments of the CMS unit. Forty-six respondents (49\% percent of the employees in the library) completed the entire survey, with a handful of partially finished responses. Responses were received from almost all of the eleven main library units and regional campus libraries in the USU Libraries organization, with only three respondents indicating a preference to not identify the unit to which they reported. The largest number of survey responses came from the Reference and Instruction unit (which is also the largest library unit), accounting for just over a quarter of all responses. One hundred percent of the personnel in the Collection Development and Government Documents units (the two smallest units) answered the survey. The rest of the 
departments averaged around 30\% percent of their staff as respondents, with just the Systems unit having no respondents. (See Figure 10.)

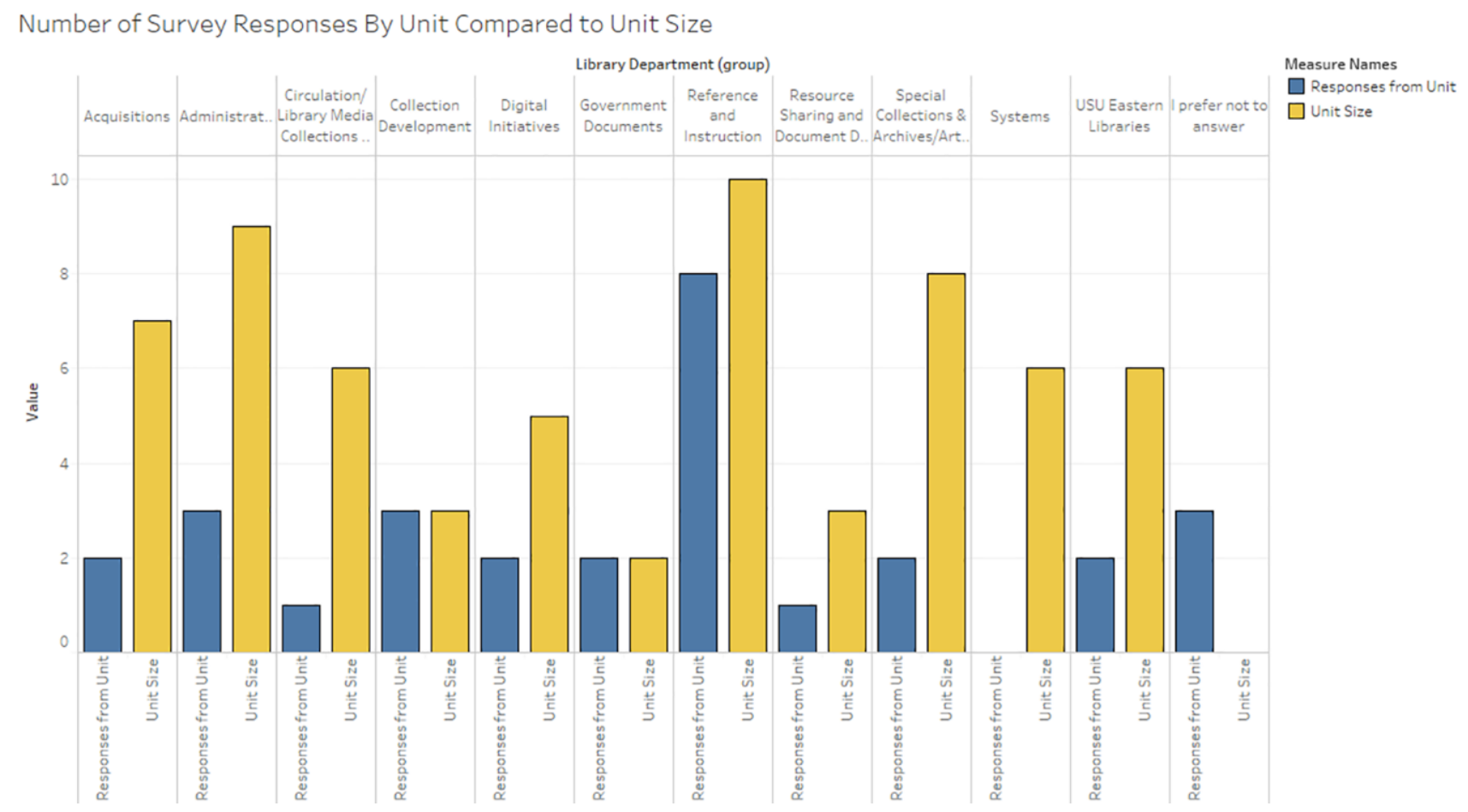

<Fig. 10. Number of Survey Responses by Unit Compared to Unit Size. >

The survey asked respondents about the frequency and reasons for their interactions with the CMS unit members, how the unit facilitated their (respondent's) day-to-day work, what the unit could do better, what skills CMS unit members should have, their (respondent's) understanding and attitude toward new services and initiatives the CMS unit provided, and the name of their (respondent's) own unit. No question other than the agreement to the terms and conditions of the survey was required and every multiple-choice question provided an option for "I prefer not to answer." Therefore, the number of responses for each question varied.

\section{Perceptions of the Unit}

To fully understand current library staff perceptions of the Cataloging and Metadata Services unit, respondents were asked to describe the ways the unit assisted them in their day-to-day work. In response, a vast majority answered that the unit made library materials accessible to 
patrons and staff. Although a seemingly obvious answer to the question, it validated the importance of this crucial step in the workings of the library. The second most common answer was database maintenance. These two activities provide the backbone for the CMS unit and can be summarized best by the following survey quotations:

"They provide a necessary part of the process of making new materials available and troubleshooting access to existing resources."

"Their work is essential for mine. Reference isn't possible without good metadata."

Other activities that aided them in their work included the willingness of CMS staff to not only help patrons find what they need directly, but also to explain and share their knowledge and expertise with other staff members so they can better serve patrons as well. The respondents were also impressed with the CMS unit's continual review and updating of workflows and procedures in response to the ever-changing atmosphere of the Library.

While the answers were all extremely positive, several mentioned that CMS members have "behind the scenes work," but they were not sure what that work entailed. This appears to support the literature assertions and highlights the need to educate other library staff about the overall work of the unit and the additional job responsibilities unit staff perform outside of cataloging materials.

Building upon the foundation of how the CMS unit assists library staff in their day-to-day work, the next step was to ask a free-response question about what skills CMS staff members should have to be effective in their positions. Not surprisingly, the top answer by far was the ability to catalog library materials, including metadata creation. Many answers were even more definitive 
and included knowledge of cataloging and metadata rules and standards, subject headings and classifications, and how to catalog different formats of materials. This basic knowledge was followed by the desire for good communication skills which, according to the survey, should predominantly focus on keeping other staff in the library aware of changing rules and standards and how that affects their work as well as how those changes impact library users. Subsequent proficiencies in diminishing order included the need to be detail oriented, capacity to balance quality work with sufficient quantity of work to meet library demands, good analytical and technical skills, ability to keep up with the ever-changing library and cataloging fields, and realizing how patrons use our materials in order to enhance access to those items. Finally, library colleagues also listed such aptitudes as being a self-motivator, having supervisory experience, familiarity with project management, and understanding how cataloging and metadata workflows fit into the larger picture for the Library and the University as a whole.

The final question given to gauge perceptions of the CMS unit was whether library coworkers felt that the work done in the Cataloging and Metadata Services unit contributed to the scholarship in the field of library and information science. Approximately two-thirds responded with a resounding yes. Furthermore, many answered that they were also familiar with specific examples of scholarship work done by members of the CMS unit staff. Most of the remaining respondents were unsure if Cataloging staff were involved in scholarship in the library field. This left only a couple of respondents who answered that they were not knowledgeable enough to know if the unit staff members did scholarship activities or published anything other than Cataloging standards.

Overall, the perceptions of the unit were very positive, with a recognition of the central role of cataloging in making library collections accessible. This deviates from many of the perceptions portrayed in the literature, which may possibly be explained in different ways. Library staff 
members will understandably be loath to criticize colleagues in a survey that will be analyzed by those same colleagues, even with anonymity. A third party analysis of the data, or even an aggregated survey that combined more than one institution would likely get more accurate accounts of perception. This would be an intriguing study to pursue in the future. However, even considering this, the perceptions of the catalogers in general are probably not as dire as much of the literature has made out. While some negative perceptions of (albeit stereotypical) traits of catalogers may persist, they often co-exist with a strong positive regard for the work that is done by cataloging and metadata librarians, as well as the personnel that performs them. Reductions in cataloging staff over time and frictions between different librarian roles are often the result of internal struggles for resources to support the ceaseless onslaught of new library projects and services as libraries continue to expand their roles, looking to find once again that "sure footing" as the respected information professional in a digital age of immediate information.

\section{Feedback on Services}

Survey respondents were asked "What can the Cataloging and Metadata Services do better to help you?" in order to solicit direct information about ways the CMS unit could improve existing services or meet demands. Twenty-one survey respondents replied to this question, $20 \%$ of whom indicated that they were wholly satisfied and could not think of anything else to suggest. The remaining $80 \%$ touched on multiple topics in their response, including communication, education and advocacy, and speed.

The largest number of respondents indicated a combination of issues that highlighted the need for more communication between the CMS unit and other library units. The surprising element in these responses was the stronger emphasis on receiving cataloging or metadata education 
rather than miscommunication regarding workflows or procedures. Many respondents indicated that they would like to know more about what the unit does and how it operates, such as:

"It might be nice simply to be more educated on the work CMS does, what is and is not cataloged, under what systems--basically to have more people understand the scope of our collections and different strategies for meeting patrons' needs. "

Others wanted the unit to advocate more on its own behalf and brag about the accomplishments of its members, such as this response:

"They do a lot to help the library, but I think they need to publicize more of what they do."

The majority of requests for more education and advocacy demonstrated the potential for rethinking what was meant by this request. Education may not mean training how to catalog in MARC or batch load records, although this information would be incredibly useful. Many of the comments mentioned wanting to know WHAT the unit did, rather than HOW the unit did it. In fact, the responses about perceptions of the unit demonstrated that many respondents already knew WHAT the unit did - at least at a high level. Perhaps these units wanted a mid-level understanding of the work done in the unit - something between making material accessible and understanding the intricacies of SuDoc classification. The CMS unit will look at developing middle of the road trainings to help other library staff understand the day-to-day work of the unit without necessarily training library colleagues to do that work.

Additionally, three other comments reflected a lack of understanding about the division of labor in the department and the status of current projects. Comments ranged from questions about who to contact for specific tasks to requests for specific projects to be completed. This 
highlighted the need to make the work of the department more transparent for library colleagues.

Four responses (19\% of the total responses) included an element relating to the speed of the work done in the CMS unit. Comments ranged from mentioning specific projects the respondent wished were addressed more quickly to simple general statements such as "Be faster." Of the requests for faster turnaround times for cataloging workflows and projects, $50 \%$ came from the Collection Development unit, 25\% from Special Collections and Archives and Art Book Room unit, and $25 \%$ preferred not to indicate their unit.

\section{Feedback on Initiatives}

\section{Single Service Point Initiative}

Survey respondents were asked, "Have you used the single service point model that Cataloging has put in place?" to determine awareness and usage of the service. They were also asked "Has the single service point model worked for you - why or why not?" to gather feedback on the strengths and weaknesses of the program.

The majority of respondents were not aware of or not sure they had used the single service point model, which was evident by respondents' confusion about the terminology used to describe the service. This outcome suggests a need for better branding of the single service point model, as well as a more targeted advertising and education about the system in general. A minority of respondents answered that they had not used the service, and working under the assumption that these individuals knew about it but did not have cause to use it, indicates that there is not a necessity among all staff to engage with the Cataloging department to report 
issues or request assistance. The commentary provided by individuals who did not use the service echoed the need to increase awareness of the program.

The remainder of respondents, about one-third, indicated that they had used the service. Among those individuals, the commentary was highly positive. Generally, the service seems to have improved the process of troubleshooting and fixing problems in the catalog, and has done so in a quick and efficient manner. Those who had used the service also reported that it was very helpful to have only one person to go to instead of being required to search for assistance among several staff members. Respondents' only criticism was not knowing what to do in the case the single service point person was not available when needed.

\section{Infographics and Education Initiative}

Respondents were asked, "Have the infographics developed by the Cataloging and Metadata Services department impacted your view of the work done in the Cataloging Department? If so, how have they impacted you?" to determine if the information related to them using these infographics improved their perceptions of the work done by the department. Most of the respondents indicated that they had seen the infographics and that they did affect their view.

Those who responded that the infographics influenced their view mostly reported that the information was educational and increased their understanding of what cataloging work entails. They also liked the method and ease of disseminating the information using bright, colorful, and succinct posters to highlight important facts and indicated being inspired to do the same for their own departments. Among the few individuals who responded that the infographics did not impact them, all related that they already knew about the department's work and achievements so were naturally not influenced by the information. Overall, the use of infographics to inform 
and celebrate achievements was highly successful, considering the encouraging feedback received from library staff outside the department.

\section{Comparing the Data}

Both the interaction assessment and the survey provided valuable quantitative and qualitative data points about the perceptions of the CMS unit and its services. From an internal perspective, the unit's ability to map out the prevailing patterns of communication using data instead of anecdotal feedback helps in strategically addressing communication deficits and capitalizing on communication strengths. It also permits a better visualization of the ways in which our colleagues' perceptions of their own communication patterns with the CMS unit differed from the quantified data. When comparing the results of both the perceptions survey and the interaction assessment to one another, a few interesting trends emerged.

The first trend involved the frequency of interaction between the CMS unit and other library units. The library units with the greatest accuracy in perceiving their interaction with the CMS unit were also the ones with which the unit interacted the most. Overall, other library units tended to underestimate the amount of interaction they had with the CMS unit.

When the interaction logs were parsed, the data was graphed to show the percentage of days, weeks, and months that interactions occurred in the allotted assessment period, which, as mentioned previously comprised 18 days over 4 weeks during 1 month. Figure 11 below shows the percentage of days, weeks, and months where interactions occurred with each department. It contrasts those recorded interactions with the expected rate of interaction reported by other library unit members in the survey. 
In the survey, respondents were asked, "On average, how frequently do you interact with a Cataloging and Metadata Services staff member?" Options included Daily, Weekly, Monthly, Intermittently, or Never. Four units had at least one respondent who indicated that they interacted daily with the CMS unit. Overall, the most common response was "weekly." Only two units had at least one respondent who reported meeting only monthly with the CMS unit staff; and three units had at least one respondent who reported meeting only intermittently with CMS unit staff. No respondents expected to never interact with the CMS unit, so this option is excluded from the data graphs.

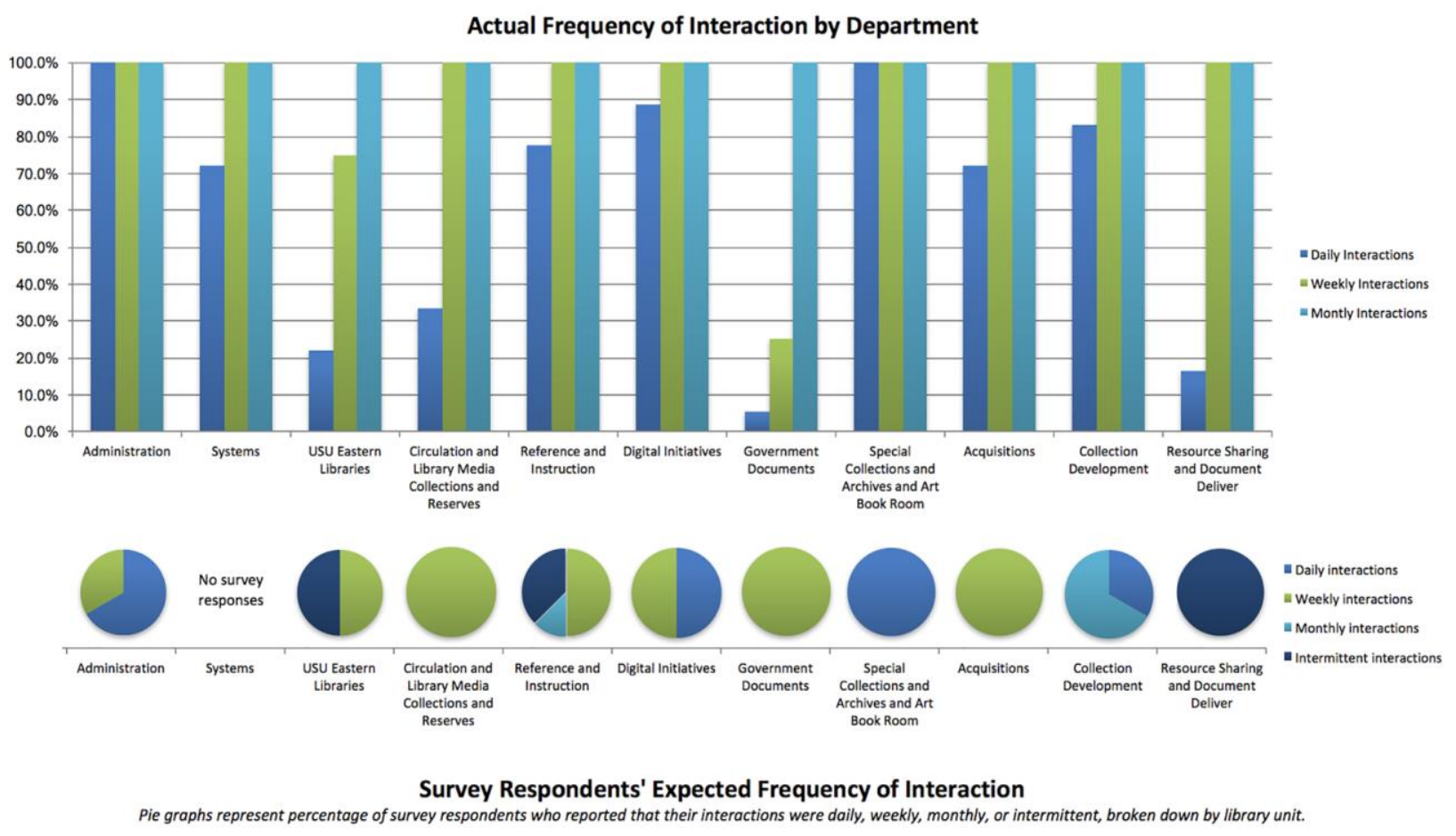

<Fig. 11. Actual versus Expected Frequency of Interaction.>

When comparing these expected interactions against the recorded data, four units were fairly accurate: Administration, Circulation and Library Media Collections and Reserves (hereafter called Circulation), Digital Initiatives, and Special Collections and Archives and Art Book Room (SCA). Administration staff members perceived their interactions with the unit to be either daily or weekly. The Associate Dean for Technical Services, the direct supervisor for the CMS unit, is 
considered part of the Administrative unit so daily interactions with that unit are not unexpected. Daily interactions between the SCA unit and the CMS unit were expected by the respondents from SCA and aligned with the recorded unit interactions.

With the exception of Collection Development, all of the units with daily interactions with the CMS unit had an accurate perception of their interactions. Daily interactions with Collection Development happened over $80 \%$ of the days recorded in the interaction logs, but only $33 \%$ of the Collection Development unit (1 individual) perceived meeting daily with CMS unit staff. The other two-thirds of the unit indicated only interacting monthly. Due to anonymity measures taken in both the survey and the interaction logs, it is unknown if this individual respondent is responsible for the majority of these interactions. However, as stated previously, the Collection Development unit shares a space with the CMS unit, so considering their close proximity as well as the over $80 \%$ daily interaction rate recorded, the expectations contrast significantly with the recorded interactions.

Respondents from the Acquisitions unit were unanimous in expecting weekly interactions, but considering the over $70 \%$ rate for daily interactions, it appears odd that more respondents did not expect interactions more frequently than weekly. The same holds true for the Reference and Instruction unit, which had interaction numbers that resembled the Acquisitions unit. Respondents from the Reference and Instruction unit expected weekly, monthly, and intermittent interactions, but the recorded data showed over $70 \%$ daily interactions.

On the opposite side of the spectrum, the Government Documents unit, $100 \%$ of whose staff responded to the survey, unanimously anticipated weekly interactions with the CMS unit staff, but only interacted $25 \%$ of the weeks during the interaction log assessment. The Resource Sharing and Document Delivery (RSDD) unit anticipated only intermittent interactions, which is 
striking because the RSDD unit interacted with a CMS unit staff $100 \%$ of the weeks involved in the interaction log. However, RSDD had only one respondent to the survey $(1 / 3$ of their staff members), so the perceived frequency of interaction may not be accurate for the unit as a whole.

Comparing the recorded reasons for interaction against the perceived reasons for interactions presents a second series of interesting trends. (See Figure 12.) Similar to the frequency of interaction trend, the perceived reasons for interactions were often under-reported by other library units and no single unit was $100 \%$ accurate in identifying all of the categories for interactions that occurred. The more discerning units were those that interacted with the CMS unit the most. Lastly, what do the two categories of interactions that were the most overperceived (database questions and patron-driven questions) mean for the CMS unit?

\begin{tabular}{|c|c|c|c|c|c|c|c|c|c|c|c|c|c|c|c|c|c|c|c|c|c|c|}
\hline \multirow[b]{3}{*}{ Dottabase questions } & \multicolumn{2}{|c|}{ Accuistitions } & \multirow{2}{*}{\multicolumn{2}{|c|}{\begin{tabular}{|c|} 
Administration \\
Recorded Perceived
\end{tabular}}} & \multirow{2}{*}{\multicolumn{2}{|c|}{$\begin{array}{l}\text { Circulation/Library } \\
\text { Nedia Collections } \\
\text { Recorded Perceived }\end{array}$}} & \multicolumn{2}{|c|}{$\begin{array}{c}\text { Collection } \\
\text { Development }\end{array}$} & \multicolumn{2}{|c|}{ Dightal hitiditives } & \multicolumn{2}{|c|}{$\begin{array}{l}\text { Government } \\
\text { Documentsts }\end{array}$} & \multicolumn{2}{|c|}{$\begin{array}{l}\text { Reference and } \\
\text { Instrution }\end{array}$} & \multicolumn{2}{|c|}{$\begin{array}{c}\text { Resource Sharing } \\
\text { and Document } \\
\text { Delivery }\end{array}$} & \multicolumn{2}{|c|}{$\begin{array}{c}\text { Specal Collections } \\
\text { and Archives and Art } \\
\text { Book Room }\end{array}$} & \multicolumn{2}{|c|}{ Systems } & \multicolumn{2}{|c|}{$\begin{array}{l}\text { USu Eastern } \\
\text { Lubraries }\end{array}$} \\
\hline & Recorded Pe: & erceived|R & & & & & Recorded P & erceived: & Recorded $P$. & Perceived|: & Recorded P & Percevered! & Recorded Pe & ereived? & Recorded Pe & enceived! & Recorded Pe & Perceived & Recorded Pe & Perceived| & Recorded P & Perceived \\
\hline & $0.0 \%$ & $0.0 \%$ & $0.0 \%$ & $66.7 x$ & $0.0 \%$ & $0.0 \%$ & $21 \%$ & 33.38 & 12336 & $100.0 \%$ & $0.0 \%$ & 50.008 & $0.0 \%$ & $37,5 \%$ & $0.0 \%$ & 0.08 & $1.6 \%$ & $50,0 \%$ & $13.9 \%$ & $0.0 \%$ & $0.0 \%$ & $0.00 \%$ \\
\hline Drop oth/picup materials & $8.7 \%$ & $0.0 \%$ & $3.7 \%$ & $0.0 \%$ & $14.3 \%$ & $100.0 \%$ & $10.6 \%$ & $66.7 \%$ & $3.5 \%$ & $0.0 \%$ & $0.0 \%$ & $50.00 \%$ & $5.6 \%$ & $12.5 \%$ & $0.0 \%$ & $0.0 \%$ & $10.1 \%$ & $100,0 \times$ & $5.6 \%$ & $0.0 \%$ & $0.0 \%$ & 0.00 \\
\hline General librany issues & 4,48 & $0.0 \%$ & 26.68 & $100.0 \%$ & $21.4 \%$ & $0.0 \%$ & 1498 & 33.37 & $0.0 \%$ & $50.0 \%$ & $0.0 \%$ & 0.08 & 0.08 & $0.0 \%$ & 8.38 & 0.08 & $79 \%$ & $50,0 \%$ & $0.0 \%$ & $0.0 \%$ & $0.0 \%$ & $0.0 \%$ \\
\hline Methings, Committees, Projects, or Traninges & 6.55 & $0.0 \%$ & 25.76 & 100.04 & 14.35 & 0.068 & $145 \%$ & 33.38 & $31.6 \%$ & $100.0 \%$ & $50.0 \%$ & $50.0 \%$ & 13.98 & $50.0 \%$ & 50.05 & $0.0 \%$ & 2228 & $100,0 \%$ & 25.05 & $0.0 \%$ & $0.0 \%$ & $0.0 \%$ \\
\hline Patron-diviven questions & $0.0 \%$ & $50,0 \%$ & $0.0 \%$ & 33.34 & $0.0 \%$ & 0.06 & $0.0 \%$ & $33.3 \times$ & $0.0 \%$ & $50,0 \%$ & $0.0 \%$ & 0.06 & 288 & $75.0 \%$ & $0.0 \%$ & 0.06 & $1.6 \%$ & $0.0 \%$ & $13.9 \%$ & $0.0 \%$ & $0.0 \%$ & $0.0 \%$ \\
\hline Procedures/Workflow issues & 2395 & $100,0 \%$ & $8.3 \%$ & $1000 \%$ & $14.3 \%$ & 0.08 & 1498 & $1000 \%$ & 7.08 & $100,0 \%$ & $0.0 \%$ & $100,0 \times 2$ & $28 \%$ & $0.0 \%$ & 33.35 & $100.0 \%$ & $11.1 \%$ & 100,00 & $0.0 \%$ & $0.0 \%$ & $0.0 \%$ & 500.0 \\
\hline Publicservice desks & $0.0 \%$ & $0.0 \%$ & 0.98 & $33.3 \times$ & $21.4 \%$ & $0.0 \%$ & $0.0 \%$ & $33.3 \%$ & $5.3 \%$ & $0.0 \%$ & $0.0 \%$ & 0.08 & 8336 & $37.5 \%$ & $0.0 \%$ & 100000 & $11.1 \%$ & $0.00 \%$ & 8.35 & $0.0 \%$ & $0.0 \%$ & $0.00 \%$ \\
\hline Request assistance & $2.2 \%$ & $100.0 \%$ & $5.5 \%$ & $66.7 \times$ & 7.18 & $0.0 \%$ & $4.3 \%$ & $66.7 \times$ & $7.0 \%$ & $50.0 \%$ & $50.0 \%$ & $100.0 \%$ & 8.35 & $25,0 \%$ & $0.0 \%$ & $100.0 \%$ & 3.26 & $50,0 \%$ & $25.0 \%$ & $0.0 \%$ & $0.0 \%$ & $50,0 \%$ \\
\hline Social & $45.7 \%$ & $50,0 \%$ & $110 \%$ & $66.7 \times$ & $7.1 \%$ & $0.0 \%$ & $34.0 \%$ & 33.38 & 28.18 & $100.0 \%$ & $0.0 \%$ & $50.0 \%$ & 288 & $50,0 \%$ & $0.0 \%$ & $0.0 \%$ & $28.6 \%$ & $500 \%$ & $5,6 \%$ & $0.0 \%$ & $0.0 \%$ & $0.0 \%$ \\
\hline Other & $8.7 \%$ & $0.0 \%$ & $18.4 \%$ & 0.06 & $0.0 \%$ & $100.00 \%$ & $4.3 \%$ & $0.0 \%$ & $5.3 \%$ & $0.0 \%$ & $0.0 \%$ & $50.0 \%$ & $528 \%$ & $0.0 \%$ & 8.38 & 0.05 & $27 x$ & $0.0 \%$ & 288 & $0.0 \%$ & 100,05 & 50,00 \\
\hline Not supplied & $0.0 \%$ & 0.08 & $0.0 \%$ & $0.0 \%$ & $0.0 \%$ & 0.08 & $0.0 \%$ & $0.0 \%$ & $0.0 \%$ & $0.0 \%$ & $0.0 \%$ & 0.04 & 288 & $0.0 \%$ & $0.0 \%$ & 0.05 & $0.0 \%$ & $0.0 \%$ & $0.0 \%$ & $0.0 \%$ & $0.0 \%$ & $0.0 \%$ \\
\hline Total Catefories & 1 & 4 & 8 & 8 & 7 & 2 & 8 & 9 & 8 & 1 & 2 & 1 & 8 & 7 & 4 & 3 & 10 & 7 & 8 & 0 & 1 & 3 \\
\hline
\end{tabular}

<Fig. 12. Recorded versus perceived reasons for interaction.>

There were ten categories used to group reasons for interactions in both the survey and the interaction logs: database questions, drop off/pick up materials, general library issues, meetings, patron-driven questions, procedures and workflow issues, public service desks, requesting assistance, social, and other. Overall, the CMS unit averaged 6.45 interaction 
categories with each library unit. However, the units who took the survey tended to underanticipate their interactions with the CMS unit, averaging 5.7 interaction categories per unit.

When compared with the data collected in the interaction logs, those units with the most insight into their reasons for interacting with CMS staff were: Administration, Collection Development, Reference and Instruction, and Special Collections \& Archives. Three of the four units indicated that they interacted daily with the CMS unit, which provides further evidence that perception of regular interaction improves the understanding of the role the CMS unit plays in the day-to-day work of other library units. For the purposes of this evaluation, perceptions seen as accurate were those where an interaction was perceived and also recorded. This evaluation did not compare the percentages for the recorded or perceived reasons for interaction because those percentages measure two different values. For recorded interactions, the percentages indicate what portion of all of the interactions that category encompassed for each unit. For the perceived interactions, the percentage indicated what portion of the respondents in a given unit selected that category in the survey. Respondents were not asked to weigh how often that interaction occurred, just whether or not they felt they interacted with a CMS staff member for the reason presented.

Most interesting of all was how often other library units anticipated that their interactions with the CMS unit would involve a question about a database or soliciting an answer on behalf of a patron. Six units selected "Database questions" and five units selected "Patron-driven questions" as reasons for interacting with the CMS unit. Although the unit prides itself on maintaining a robust working knowledge of the library catalog and the digital library (the two databases it regularly contributes to), the only other units who actually interacted with the CMS unit about those databases also have an active part in maintaining them: Systems and Digital Initiatives. This lead the CMS unit to question why this was the case. The obvious answer is 
that the Systems and Digital Initiatives were conferring with the CMS unit about an issue in the databases rather than asking a question outright. For the rest of the library units, either the databases rarely caused problems or those issues were not making it to the CMS staff. From this data, the unit identified the need to re-examine the single service point initiative to determine if a more effective method could be employed.

Likewise, patron driven questions were likely answered in other units before getting to the CMS unit. With the exception of a select few instances during the interaction log assessment time period, other units asked very few questions on behalf of a patron. In previous years, patron driven questions mostly revolved around investigations into the status of a book and when it would be ready for checkout. A change in this type of interaction can be due to a number of external and internal factors: shelf ready workflows that bypass the CMS unit, increasing patron demand for e-resources instead of print material, or even streamlined rush cataloging procedures that have reduced the amount of issues that keep patrons waiting for material.

\section{Implementing what we have learned}

The process of tracking interactions, developing new service initiatives, and surveying the landscape of library peer perceptions provided a valuable self-reflection exercise for the Cataloging and Metadata Services unit. In many ways, it encouraged the unit to begin to reimagine itself and its role in the larger framework of the library. The data, admittedly, only illustrates the communication patterns of the CMS staff and could benefit from greater context, seeing how it compares to the broader interaction trends among all library staff. This possibility is outside the purview of the unit, but would be an intriguing study to undertake in the future. The immediate takeaways, however, provided an ideological foundation for redeveloping the 
unit outreach model, including: 1) understanding the importance of regular interaction and 2) using education as advocacy.

\section{Recurring Interaction as a Priority}

Every interaction is an opportunity to develop a personal connection to library colleagues. The reasons to create personal connections go well beyond making friends or having an enjoyable work environment, although these are admirable goals in their own right. Regular interactions create small but important opportunities to exchange ideas and gain insight into what is happening in other parts of the library - as well as giving those units an idea of what is happening in the world of cataloging and metadata. Over time, these interactions and discussions build on one another and form the perceptions and impressions that shape how units regard and appreciate the work that is done around the library. In these interactions, it is as important to gain an understanding of the work and personnel in other units, as it is to generate interest in the work of one's own unit. Valuing the work that is performed in other units provides not just a feel-good work environment, but also the ability to see how cataloging and metadata skills can actively benefit and animate the work done in other library units.

Taking this into account, the CMS unit identified other key library units where actual or perceived interactions were the lowest and invited representatives from those units to work with our single service point coordinator to redevelop the service. The cross-departmental team was charged with analyzing the best possible model to meet the needs of the rest of the library. They were also given the responsibility for branding the service, advertising, and even recommending possible changes to the physical layout of the CMS unit space. This provided an ongoing reason for interaction with groups underrepresented in the interaction assessment while also seeking out feedback and input from the intended users of the single service point 
initiative. The group was also encouraged to work together to develop a presentation or scholarly deliverable to further invest participants in developing a positive program and provide a longer lasting connection between the units. While the work of this group is still in progress, the potential outcomes are numerous: increase communication with units where a deficit was detected, create interaction opportunities for members of the CMS unit who are not in contact with other units frequently, develop a service that will meet the needs of the other units in the library, increase awareness of that service, and engage library colleagues by inviting them to be stakeholders in the work and functionality of the CMS unit.

The unit also arranged for opportunities to train with other library peers in collaborative professional development settings. Typically, the cataloging and metadata staff has sought out training specific to the work of the unit. In the interest of increasing interactions, the unit went outside these traditional areas and explored more universal topics, such as leadership and communication styles, or current library trends, such as open educational resources and data management, as a joint venture with library colleagues from other units. The last two topics, in particular, provide a platform to explore the commonalities shared by each library discipline, allowing CMS staff to discuss the impact of cataloging and metadata standards in each of these areas and, vice versa, allowing other units to discuss the application of these issues in their fields.

Less attractive, but still vitally important, the CMS unit re-examined some of the more common interaction potentials mentioned at the beginning of the article: service desk opportunities and committee service. The unit adjusted committee appointments to more evenly spread duties among the staff and provide more opportunities for interaction. A few, but not all, members felt comfortable enough to assume new public service desk duties. Additionally, some also began 
observing Reference and Instruction Librarians as they worked in the classrooms demonstrating databases and resources for students.

There are other possibilities for improving and increasing interactions with other units in the library. For instance, occasionally attending other unit's meetings to observe processes and learn about broader topics or issues that are being addressed in the library. Doing this may help increase the visibility and accessibility of the unit's skills and open up new ways they can be utilized elsewhere in the library. The CMS unit will also explore ways in which our research and scholarship intersect similarly with other staff efforts to possibly conduct more comprehensive studies and assessment of library services.

\section{Education as Advocacy}

Interpreting and implementing requests for more information and education about the work of the CMS unit was more challenging than developing interaction opportunities. Educating library colleagues on the work of the unit could range from full-blown training on cataloging and metadata standards and workflows to simply talking more about the projects and issues that keep the unit busy. Finding the right tone and level of information is tricky, especially as expectations differ between other library units and colleagues. The CMS unit identified three potential areas to meet the education and advocacy recommendations elicited from the survey: cataloging and metadata training, project visibility, and pushing out communications. The overall purpose of these outreach and education initiatives was not necessarily to cross train library colleagues, but rather to develop a foundation for understanding the principles that drive the work of the unit.

This emphasis on developing a common language and understanding of information architecture is an essential piece of the education component. The CMS unit identified the need 
to create short, digestible trainings on metadata and cataloging concepts that could be presented periodically - either in the regular meetings of other departments or the library's biweekly all-staff "table talks" gatherings. These bite sized educational pieces should explain cataloging and metadata concepts through the lens of the work done in other library units. For instance, a short demonstration and hands on exercise about how indexing works in the discovery layer can be used to facilitate the work of the Reference and Instruction unit or anyone working at a service desk. A few test tutorials and exercises are currently in development in the CMS unit, but a field-wide collaboration to build and share micro-lessons such as these could capitalize on the general knowledge of the field and expand the collective impact of cataloging units.

From the survey, the term education was also used to mean a general understanding of the projects the unit is working on and the current progress made on those projects. In the survey, library units that requested this type of communication were not involved in the regular workflow of the CMS unit and therefore did not have a forum for knowing what projects were tying up the staff and time of the unit. To address this communication deficit, the unit developed a shared working space in a cloud based storage system utilized by the library. These shared spaces were used to visibly document any projects that the unit worked on, including project charters, time and cost estimates, and procedures. In addition, the unit compiled an overarching tracking spreadsheet that listed and ranked every project in order of priority to the library. Units wanting to know where their project stood in the queue can consult that spreadsheet at any time. Units that simply want to know what the CMS unit is working on can likewise see the priorities, current projects, and the estimated time to complete the backlog. This ongoing cumulative estimate for backlogs has been instrumental in helping the unit make the case for continued staffing and additional student help. 
While the existence of a project tracking spreadsheet has been helpful to refer other library units to, it does not take the place of broadcasting information about the unit. Additional steps have been identified to push out information about the unit on a more regular basis, including ideas such as crafting a quarterly e-newsletter to feature the projects completed or underway in the unit, as well as recent accomplishments and scholarship done by unit members. This same kind of content would also be transferred to the unit's blog, where it shares information about workflows used in the unit.

There are a number of other ways to advance education efforts. For example, continuing to use infographics to distill and disseminate information about the CMS unit's activities and accomplishments. Placing them more strategically throughout the library will likely yield the same positive results as they have already, but on a larger scale. Determining central locations where other units, students, and faculty frequent will further promote cataloging as a public service to the university. Together with infographics, the CMS unit's efforts can be published online and openly accessible using websites, blogs, and newsletters. Sharing workflows, procedures, and innovations will not only garner more attention to the CMS unit's contributions to the field, but also help other technical services units follow suit.

\section{Conclusion}

The Cataloging and Metadata Services unit at USU recognized a clear need to promote our services and advocate for better understanding of our impact in the library and in the larger scope of librarianship. In this effort, we sought to determine the source of commonly held perceptions and ways to proactively shift these views to truly reflect the reality of the public service we offer. Data gathered from interaction assessment revealed a few surprising results. First, most interactions were of a social nature and therefore contradicted established 
stereotypes. Second, interactions with other technical services units were comparatively rare which suggests a possible need to engage with these other units more directly. Third, regular interactions yield better understanding of the role and work of the unit.

As a result of conducting this survey research to determine perceptions and measure the effectiveness of our services, we found that opinions of the CMS unit were much more positive than expected. Moreover, despite a highly praised effort to educate using infographics, there were expressed desires to know more about cataloging work. Feedback also revealed a lack of understanding about some of our services, which reiterated the need to continue our education efforts.

Moving forward, building upon previous endeavors to educate others about cataloging scholarship, innovation, and impact in the library, efforts will be made to implement what has been learned from this interaction assessment. The strategy for doing so includes: increasing our level of collaboration, celebrating our achievements in a more visible format, utilizing opportunities to promote services to staff and administration, publicizing existing partnerships that directly meet user needs, enhancing physical space to encourage use of the single service point model, developing task-based micro tutorials to demonstrate cataloging and metadata concepts, and growing our online presence by sharing workflows, procedures, and scholarship.

\section{Notes}

1. Juliya Borie, Kate MacDonald and Elisa Sze, "Asserting Catalogers' Place in the 'Value of Libraries' Conversation.” Cataloging \& Classification Quarterly, 53:3-4 (2015): 352.

2. Ibid.

3. Shawne D. Miksa, "You Need My Metadata: Demonstrating the Value of Library Cataloging," Journal of Library Metadata, 8:1 (2008): 23. 
4. Daniel CannCasciato, "An Essay on Cataloging," Library Philosophy and Practice. Paper 468 (2010).

5. Borie, MacDonald and Sze, “Asserting Catalogers' Place,” 355.

6. ALCTS, "Value of Cataloging Librarians," Associations for Library Collections \& Technical Services, June 13, 2006, http:/www.ala.org/alcts/resources/org/cat/catlibvalue (accessed February 27, 2017).

7. Daniel CannCasciato, "An Essay on Cataloging," 2.

8. David Banush, "Stepping Out: The Expanding Role of Catalogers in Academic Libraries and Academic Institutions," Cataloging \& Classification Quarterly, 45:3 (2008): 81-82.

9. Ibid., 81.

10. Heidi Lee Hoerman, "Why Does Everybody Hate Cataloging?," Cataloging \& Classification Quarterly, 34:1-2 (2002): 30.

11. Jeanne M. K. Boydston and Joan M. Leysen, "ARL Cataloger Librarian Roles and Responsibilities Now and In the Future," Cataloging \& Classification Quarterly, 52:2 (2014): 229.

12. Ibid., 244.

13. David Banush, "Stepping Out," 84.

14. Sandy L. Folsom, "Out of the nest: the cataloger in a public services role, Library Collections," Acquisitions, and Technical Services, Volume 24, Issue 1 (Spring 2000): 67-68.

15. Laura Turner and Alejandra Nann, "Venturing from the 'Back Room': Do Technical Services Librarians Have a Role in Information Literacy?" Proceedings of the Charleston Library Conference, (2014): 397.

16. Borie, MacDonald and Sze, “Asserting Catalogers' Place," 364.

17. Shawne D. Miksa, "You Need My Metadata," 3435.http://dx.doi.org/10.5703/1288284315293

18. David Banush, “Stepping Out," 89.

19. Heidi Lee Hoerman, "Why Does Everybody Hate Cataloging?," 37.

20. "USU Cataloging \& Metadata Services," last updated February 23, 2017, https://usucataloging.wordpress.com/ (accessed March 3, 2017). 
